\title{
La responsabilidad hacia la Administración en el Derecho Administrativo uruguayo*
}

\begin{abstract}
Augusto Durán Martínez
Catedrático de Derecho Administrativo en las Facultades de Derecho de la Universidad de la República y de la Universidad Católica del Uruguay. Director del Área Académica de Derecho Administrativo y Decano Emérito de la Facultad de Derecho de la Universidad Católica del Uruguay.
\end{abstract}

Resumo: O presente artigo trata da responsabilidade perante a Administração no Direito Administrativo Uruguaio. Primeiramente demonstram-se aspectos gerais da responsabilidade. Aborda-se a responsabilidade civil dos funcionários públicos, diante da Constituição de 1934, da Emenda de 1942 e da Constituição de 1952. Citam-se interpretações de doutrinadores sobre as normas constitucionais que regem o tema da responsabilidade dos funcionários públicos. Em seguida, as hipóteses de responsabilização previstas no artigo 25 da Constituição de 1952 são analisadas. Relacionam-se alguns artigos do TOCAF (Texto Ordenado de Contabilidade e Administração Financeira) com a responsabilidade administrativa e civil. Menciona-se que, para a existência da responsabilidade civil é necessária a existência de um dano, que pode ser patrimonial e moral. Por fim, sustenta-se que a Constituição deve ser interpretada de acordo com a dignidade da pessoa humana e com as tendências atuais do Direito Constitucional, para evitar irresponsabilidades e permitir a realização integral do Direito.

Palavras-chave: Direito Administrativo Uruguaio. Responsabilidade civil dos funcionários públicos. Constituição. Texto Ordenado de Contabilidade e Administração Financeira. Dano.

1 Soto Kloss, en frase que ya ha devenido clásica, expresó: "quien dice Derecho, dice responsabilidad."

Esta afirmación se explica porque siendo el derecho lo justo, ${ }^{2}$ el daño,

\footnotetext{
* Exposición formulada en el marco de Las XXXIV Jornadas Nacionales y IV Congreso Internacional de Derecho Administrativo (La Responsabilidad en el ámbito del Derecho Público), organizadas por la Asociación Argentina de Derecho Administrativo y la Facultad de Ciencias Jurídicas y Sociales de la Universidad Nacional del Litoral, en la ciudad de Santa Fe, República Argentina, del 22 al 24 de octubre de 2008.

SOTO KLOSS, E., "La responsabilidad del Estado administrador, un principio general del Derecho chileno", en VV.AA., Estudios de Derecho Administrativo. Universidad de la República. Montevideo, 1978, t. I, p. 480 y 487.

2 ARISTÓTELES. Moral a Nicómaco. Colección Austral. Espasa-Calpe S.A. Madrid, 1972, p. 134 y ss.; TOMÁS DE AQUINO. Tratado de la ley. Tratado de la justicia. Opúsculo sobre el gobierno de los príncipes. Editorial Porrúa S.A. México, 1975, p. 117 y ss.; VILLEY, M., El Derecho. Perspectiva griega, judía y cristiana. Ghersi Editor. Buenos Aires, 1978, p. 20, 22 y 23; VILLEY M., Método, fuentes y lenguaje jurídicos. Ghersi Editor. Buenos Aires, 1978, p. 75; MASSINI, C.I., Sobre el realismo jurídico. Abeledo-Perrot. Buenos Aires, 1978, p. 19; DURÁN MARTÍNEZ, A., "El derecho administrativo entre legalidad y derechos fundamentales", en DURÁN MARTÍnEZ, A., Estudios de Derecho Público. Montevideo, 2008, v. 2, p. 257 y ss.
} 
punto de partida para la responsabilidad, ${ }^{3}$ rompe el equilibrio indispensable para la vida en sociedad. Producido un daño es preciso restablecer el equilibrio alterado.

La afirmación de Soto Kloss se explica también porque el derecho supone seres libres. Solo un ser que actúa en ejercicio de la libertad da cuenta de sus actos.

Sin responsabilidad, pues, no se puede ni siquiera imaginar el Derecho.

2 Por eso la responsabilidad existe tanto en el ámbito del derecho privado como en el del derecho público. Y por eso la responsabilidad se compromete cualquiera sea la naturaleza del daño, cualquiera sea el sujeto que lo comete y cualquiera sea el sujeto que lo sufre.

3 Como diversa puede ser la naturaleza del daño y distintos los sujetos que lo pueden ocasionar o sufrir, habrá distintas responsabilidades. Así hablamos de responsabilidad penal, política, administrativa y civil o patrimonial.

4 Conforme al título de este trabajo, quedan fuera de su objeto la responsabilidad penal y la política porque en ninguno de esos casos se responde ante la Administración. Quedan sí incluidas la responsabilidad administrativa y la civil o patrimonial.

5 De esos dos tipos de responsabilidad centraré mi atención en la que puedan incurrir los funcionarios públicos. No referiré a la que puedan incurrir los particulares.

Y de la responsabilidad de los funcionarios, haré especial hincapié en la patrimonial. Solo aludiré a otros tipos de responsabilidad en la medida en que ello sea indispensable para el tratamiento de nuestro tema.

\section{II}

1 El único artículo constitucional que regula de algún modo la responsabilidad civil de los funcionarios públicos hacia la Administración es el 25.

2 Para su debida comprensión es preciso tener en cuenta previamente el artículo 24. Pero para comprender ciertas interpretaciones que se han efectuado al respecto, es preciso partir del artículo 24 de la Constitución de 1934.

${ }^{3}$ HENAO, J.C., El daño. Universidad Externado de Colombia. Bogotá, 2007, p. 30. 
3 El artículo 24 de la Constitución de 1934, en redacción mantenida en la enmienda constitucional de 1942, decía:

Será civilmente responsable cualquier funcionario que, en ejercicio de la función pública que le estuviere confiada, y con incumplimiento de los deberes que el cargo le impone, cause perjuicio a tercero.

Responderán subsidiariamente, el Estado, los Municipios, los Entes Autónomos, o Servicios Descentralizados, o el Órgano Público de que dependa el funcionario, quienes serán parte necesaria en los juicios que se promuevan al efecto, y tendrán el derecho de repetir contra aquél lo que hubieren pagado en caso de condenación.

Ante este texto en general se sostuvo que existía una responsabilidad directa del funcionario y solo subsidiaria del Estado. ${ }^{4}$ Digo en general porque algunos autores, como Méndez, admitieron la posibilidad de una acción directa contra el Estado. ${ }^{5}$

4 Pero el texto actual, cuya redacción proviene de la Constitución de 1952, varió:

Los artículos 24 y 25 vigentes dicen:

Art. 24. El Estado, los Gobiernos Departamentales, los Entes Autónomos, los Servicios Descentralizados y, en general, todo órgano del Estado, serán civilmente responsables por el daño causado a terceros, en la ejecución de los servicios públicos, confiados a su gestión o dirección.

Art. 25. Cuando el daño haya sido causado por sus funcionarios, en el ejercicio de sus funciones o en ocasión de ese ejercicio, en caso de haber obrado con culpa grave o dolo, el órgano público correspondiente podrá repetir contra ellos, lo que hubiere pagado en reparación.

5 Ante esta normativa, la doctrina ha sostenido que no es posible la acción directa contra los funcionarios. En general se ha sostenido que procede la acción directa contra el Estado y este puede repetir contra el funcionario en caso de que este haya actuado con dolo o culpa grave. Las afirmaciones de Sayagués Laso ${ }^{6}$ y Martins, ${ }^{7}$ por ejemplo, son muy claras en ese sentido.

4 SAYAGUÉS LASO, E., Tratado de Derecho Administrativo. F.C.U. Montevideo, 1998, t. I, 7. ed. puesta al día a 1998 por Daniel Hugo Martins, p. 532 y ss.; DURÁN MARTínEZ, A., Casos de Derecho Administrativo. Universidad Católica del Uruguay-Ingranusi Ltda., Montevideo, 1999, v. 1, p. 189.

5 MÉNDEZ, A., "Relaciones entre la responsabilidad del Estado y la del funcionario", en La Justicia Uruguaya, año 1940 , t. I, p. 122 y ss.

6 SAYAGUÉS LASO, E., Tratado..., t. I,..., p. 283.

7 MARTINS, D.H., "La responsabilidad de la Administración y de los funcionarios en la Constitución uruguaya", en MARTINS, D.H., Constitución y Administración, Ingranusi Ltda., Montevideo, 1997, t. 1, p. 276. 
Parece claro, por otra parte, que esa fue la intención del legislador constitucional. $^{8}$

El literal $\mathrm{T}$ de las Disposiciones Transitorias y Especiales de la Constitución de $1952^{9}$ ha sido invocado en apoyo de la tesis indicada.

Martins al comentarlo expresó: "Esta norma constitucional no tiene historia. Apareció -sin que conste discusión alguna en torno a ella- en el proyecto de enmienda preparado por la Comisión Especial de Reforma de la Constitución de la Cámara de Representantes y fue aprobada, sin discusión alguna, en la sesión extraordinaria № 96 de dicha Cámara, celebrada el día 10 de octubre de 1951 (Diario Oficial, $N^{\circ}$ 13.553). Esta falta de antecedentes, obliga al intérprete, con mayor razón que en otros casos, a ceñirse estrictamente a la letra de la disposición, la que por otra parte, parece perfectamente clara. Según nuestra interpretación del texto constitucional, el constituyente quiso que a todos los juicios iniciados con anterioridad al 25 de enero de 1952, demandando directamente al funcionario y subsidiariamente al Estado o al órgano público del que depende 'de acuerdo al art. 24 de la Constitución vigente', se siguieron en adelante contra el Estado o el órgano del Estado demandado."10

En esa misma línea interpretativa, Gros Espiell entendió que la Constitución de 1952 invertía el sistema con relación al vigente hasta ese momento y por el literal T) aludido se disponía -en virtud de la nueva solución- que los juicios iniciados contra los funcionarios automáticamente proseguían contra el Estado. ${ }^{11}$

Por mi parte, en este punto he acompañado en un principio la posición de la doctrina imperante, ${ }^{12}$ pero luego de leer el inteligente trabajo de Risso Ferrand ${ }^{13}$ sobre el tema he cambiado de opinión. ${ }^{14}$

6 Risso Ferrand, al estudiar los artículos 24 y 25 de la Constitución vigente, expresó:

\footnotetext{
8 JIMÉNEZ DE ARÉCHAGA, J., La Constitución de 1952. Cámara de Senadores. Montevideo, 1995, p. 185 y ss.; MARTINS, D.H., "La responsabilidad...", loc. cit., p. 237 y ss.; RISSO FERRAND, M., "Responsabilidad civil de los funcionarios públicos", en Segundo Coloquio. Contencioso de Derecho Público. Responsabilidad del Estado y Jurisdicción. Editorial Universidad, 1995, p. 16 y ss.

9 Este literal T) decía: "Los juicios en trámite iniciados contra los funcionarios y el órgano del Estado de que dependen, de acuerdo con el artículo 24 de la Constitución vigente, proseguirán en adelante exclusivamente contra el órgano del Estado demandado sin perjuicio de lo dispuesto en el artículo 25 de la presente Constitución."

10 MARTINS, D.H., "La responsabilidad...", loc. cit., p. 279.

11 GROS ESPIELL, H.; MARTINS, D.H., Disposiciones Transitorias y Especiales en las Constituciones del Uruguay. Ediciones De La Plaza, Colección Testimonios, Montevideo, 1999, p. 38.

12 DURÁN MARTíNEZ, A., Casos..., v. 1, p. 190.

13 RISSO FERRAND, M., "Responsabilidad civil ...", loc. cit., p. 11 y ss.

14 DURÁN MARTíNEZ, A., Casos de Derecho Administrativo, v. 6, en preparación.
} 
... parecería que de las normas mencionadas solo se desprende:

a) en primer lugar, que el artículo 24 establece la responsabilidad directa del Estado y demás sujetos de derecho público, comprendiendo todas las hipótesis posibles en que el Estado puede ocasionar daños a un tercero, con la sola excepción de los daños derivados de la actividad legislativa.

b) en segundo término, el artículo 25, sólo refiere a la hipótesis en que el Estado ha indemnizado en base al artículo 24, y pretende repetir lo pagado contra los funcionarios.

c) por último, los artículos 24 y 25 no dicen ni que la única vía por la cual los terceros damnificados pueden lograr la reparación del daño sufrido sea la del artículo 24, ni que dichos terceros no puedan demandar directamente al o los funcionarios, ya sean en forma principal y exclusiva, o en forma conjunta con el Estado.

Pues bien, si la Constitución sólo nos habla de la responsabilidad de los sujetos de derecho público y de la posibilidad de que éstos, en determinadas ocasiones repitan contra los funcionarios, ¿̇ué se debe concluir del texto constitucional respecto a los funcionarios?

Sostener que tiene una suerte de inmunidad y que su responsabilidad civil (por los daños causados en ejercicio de sus funciones o en ocasión de dicho ejercicio), sólo puede hacerse valer por la vía indirecta del artículo 25, parece que no podría admitirse, ya que dicha hipótesis no tiene base constitucional.

Parece que lo razonable sería sostener que la eventual responsabilidad directa de los funcionarios es una cuestión no regulada por la Constitución. Lo que es muy distinto a sostener que existe un vacío constitucional, que en la especie no se configura. La Carta no regula la materia y la misma queda librada a la ley.

Cabe agregar que ante el silencio del ordenamiento jurídico, la solución es claramente la responsabilidad civil de las personas físicas y jurídicas, establecida en forma elocuente, entre otras normas, en el artículo 1.319 del Código Civil.

En definitiva, la solución que estimamos correcta respecto al texto de los artículos constitucionales referidos, consiste en que:

a) la Constitución reconoce la responsabilidad directa de los sujetos de derecho público por los daños causados a terceros.

b) cuando se indemniza en base al artículo 24, y en los casos del artículo 25, se podrá repetir lo pagado contra el o los funcionarios que correspondan.

c) no se establece en nuestra Constitución ningún tipo de inmunidad o impedimento en materia de responsabilidad civil de los funcionarios, salvo la que surge en el caso exclusivo de repetición en base al artículo 25.

d) los terceros damnificados podrían optar por demandar directamente al Estado en base al artículo 24, o a los funcionarios que hayan ocasionado los daños en base a las normas legales generales, e incluso podrían demandar en forma conjunta al funcionario y al sujeto de derecho público que corresponda. ${ }^{15}$

${ }^{15}$ RISSO FERRAND, M., Responsabilidad civil ..., p. 17 y ss. 
7 Comparto la interpretación de Risso Ferrand por las razones por él indicadas.

La interpretación tradicional se basa en la historia del texto pero no se desprende del artículo 24. Es más, creo que asiste razón a Risso Ferrand en cuanto afirma que "la intención del constituyente no coincide con el texto de la norma." 16

Pero ocurre que la interpretación de la Constitución no se rige por los criterios de interpretación que el Código Civil establece para las leyes.

La interpretación constitucional debe partir del texto, y los antecedentes tienen un peso muy inferior que en el caso de las leyes pues el autor de la Constitución no es el Poder Legislativo sino el Cuerpo Electoral que en general no conoce esos antecedentes. ${ }^{17}$

No se puede ignorar por otro lado que el literal T) de las Disposiciones Transitorias y Especiales de la Constitución de 1952, que pudo servir de pauta interpretativa contextual de los artículos 24 y 25 de esa Constitución, no fue recogido por la Constitución vigente.

Por tanto, ese literal no se puede invocar para interpretar los textos actuales. Ese literal T) que, conjugado con los artículos 24 y 25 de la Constitución de 1952 pudo llevarnos a la historia de esos artículos para su interpretación, al no existir ya no puede ser empleado para interpretar la Carta vigente y nos impide invocar la historia contra el texto actual. El contexto de la Constitución de 1967 es así distinto del de la 1952, por lo que la historia de la de 1952, en el tema en estudio, no puede invocarse para la interpretación de los artículos 24 y 25 de la Constitución actual aunque estos sean iguales a los de aquella.

Esto demuestra que no podemos apegarnos a las interpretaciones efectuadas en 1952. Los criterios de interpretación de Aréchaga deben, y pueden, amoldarse a la interpretación evolutiva que propugna el neoconstitucionalismo cuando habla de la sobreinterpretación de la Constitución ${ }^{18}$ o el derecho dúctil de Zagrebelsky. ${ }^{19}$

\footnotetext{
16 RISSO FERRAND, M., Responsabilidad civil ..., p. 18.

17 JIMÉNEZ DE ARÉCHAGA, J., La Constitución Nacional. Cámara de Senadores. Montevideo, 1992, t. I, p. 150; CASSINELLI MUÑOZ, H., "La apelación para ante la Asamblea General según el artículo 303 de la Constitución", en La Revista de Derecho, Jurisprudencia y Administración, Montevideo, 1957, t. 55, p. 125 y ss.; DURÁN MARTínEZ, A., Casos de Derecho Administrativo, Montevideo, 2007, v. 5, p. 30.

18 GUASTINI, R., "La 'Constitucionalización' del ordenamiento jurídico: el caso italiano", en VV.AA., Neoconstitucionalismo (s). Edición de Miguel Carbonell. Universidad Nacional Autónoma de México. Editorial Trotta. Madrid, 2008, p. 55.

19 ZAGREBELSKY, F., El Derecho dúctil. Ley, derechos, justicia. Editorial Trotta, Madrid, 2005, p. 14 y ss.
} 
La interpretación de Risso Ferrand se adecua más que la tradicional al nuevo modelo de Estado, el Estado constitucional democrático ${ }^{20}$ basado en la dignidad de la persona humana, porque evita la configuración de islas de irresponsabilidad.

Es más, si bien comparto la opinión de que el tema de la responsabilidad civil directa del funcionario no está regulado expresamente por lo que puede ser regulado por ley, como la obligación de reparar los daños causados es de raíz constitucional - o más bien supraconstitucional — estimo que no puede ser eliminada o neutralizada por la ley.

Esta responsabilidad patrimonial del funcionario no es hacia la Administración sino hacia los particulares. Por eso, no está comprendida en el artículo 25 de la Constitución por lo que no se exige en este caso el dolo o culpa grave que el artículo 25 citado requiere para la acción de repetición. Esta responsabilidad se rige por el Código Civil, por lo que basta la culpa leve o negligencia para que se configure la responsabilidad.

Existen algunas sentencias de primera instancia que han admitido la acción reparatoria directa contra funcionarios públicos. Si bien en general esas sentencias han sido revocadas en segunda instancia, su sola aparición anuncia un cambio de jurisprudencia que inevitablemente vendrá, pues esa es la única interpretación que se adecua al Estado Constitucional de Derecho y a una interpretación del ordenamiento jurídico desde la dignidad de la persona humana.

En una reciente obra, Risso Ferrand expresó:

Si hay algo claro es que el Derecho Constitucional de hace veinticinco años poco tiene que ver con el contemporáneo. Aun cuando los textos constitucionales no hayan tenido cambios significativos en el último cuarto de siglo (como es el caso de Uruguay) es claro que se ha producido una suerte de revolución jurídica y cultural que ha afectado en definitiva la mayoría de los desarrollos anteriores. Los cambios son sustanciales y profundos y muchos de los conceptos o razonamientos que hoy se pueden aceptar sin mayores dificultades hubieran sido insostenibles en el pasado reciente o, al revés, muchos de los desarrollos aún cercanos en el tiempo, resultan en la actualidad manifiestamente insuficientes. ${ }^{21}$

Lo expuesto precedentemente es enteramente aplicable al tema en estudio. Los artículos 24 y 25 de la Constitución se mantienen inalterados

\footnotetext{
20 ALEXY, R., Los derechos fundamentales en el Estado constitucional democrático, en VV.AA., Neoconstitucionalismo (s)..., p. 31.

${ }^{21}$ RISSO FERRAND, M., Algunas garantías básicas de los derechos humanos. F.C.U., Montevideo, 2008, p. 13.
} 
desde 1952. Pero entiendo que a la luz de lo expuesto y sobre todo desde la óptica del Estado Constitucional de Derecho, la interpretación tradicional que veda la acción directa de terceros contra los funcionarios públicos parece hoy insostenible.

8 La responsabilidad regulada por el artículo 25 sí es hacia la Administración.

En estos casos el funcionario responde ante la Administración por los pagos por ella efectuados por el daño que él causó a terceros y solo responde en caso de haber actuado con dolo o culpa grave.

Vale decir que si la Administración nada pagó a terceros, nada puede reclamar al funcionario por este artículo 25. Y aun en caso de haber pagado, solo puede repetir contra el funcionario si este obró con dolo o culpa grave. Y solo puede la Administración, según Martins, reclamar lo que pagó: no puede pedir ni más, ni menos. ${ }^{22}$ En principio, creo que la afirmación de Martins es compartible, pero si la Administración sufre un daño moral, ${ }^{23}$ estimo que no existe inconveniente para acumular una acción reparatoria, por ese daño, a la de repetición.

De esta exigencia subjetiva se deduce que la acción judicial de repetición debe ser precedida por una actuación administrativa a los efectos de determinar la existencia de ese dolo o culpa grave. De esto se desprende además que si hay dolo o culpa grave hay también una responsabilidad administrativa comprometida, por lo que en la especie estamos ante un caso en que por lo menos se acumulan la responsabilidad civil y la administrativa.

Por las razones expuestas el decreto $\mathrm{N}^{\circ} 395 / 006$, de 23 de octubre de 2006, que reglamenta el cumplimiento de las sentencias contra el Estado, por su artículo 8 estableció:

Una vez cancelada la obligación, la Unidad Ejecutora iniciará un procedimiento administrativo tendiente a determinar si corresponde promover la acción de repetición contra el funcionario o los funcionarios responsables del daño

\footnotetext{
22 MARTINS, D.H., "La responsabilidad ...", loc. cit., p. 277.

${ }^{23}$ Es perfectamente admisible el daño moral en estos casos. El Dr. Leonardo Guzmán en acertado artículo periodístico escribió: "Como una bocanada de aire fresco debe recibirse la noticia de que el Tribunal de Apelaciones en lo Civil de $2^{\circ}$ Turno declaró que el Estado debe cobrar indemnización a un fiscal penal procesado por 'concusión'-coima-, en cuanto infirió 'gran menoscabo a la imagen de la justicia' y afectó la 'credibilidad de los poderes del Estado'." Y más adelante en ese mismo artículo expresó: "... es trascendente que nuestra justicia reconozca que en el Uruguay, la institución Estado puede ser víctima de daño moral. Al sostenerlo así, confirma que nuestro Estado no es solo 'la diferencia entre gobernantes y gobernados' y es, y debe ser, ético en su base, su gestión y su propósito." (GUZMÁN, L. Nuestro Estado, ético. El País, Montevideo, $1^{\circ}$ ago. 2008, p. A5).
} 
causado, de acuerdo a lo establecido por el artículo 25 de la Constitución de la República, remitiendo al Ministerio de Economía y Finanzas copia autenticada de todos los antecedentes administrativos y judiciales relacionados al caso y su opinión sobre la procedencia de ejercer la acción de repetición.”

Este artículo impone la iniciación del procedimiento administrativo aludido luego del pago, pero en realidad nada impide que esa investigación administrativa o, en su caso, sumario, se efectúe antes, cuando la Administración tome conocimiento de la demanda reparatoria, o aun con anterioridad, cuando tome conocimiento del perjuicio causado.

El artículo 25 de la Constitución dice que en los supuestos comprendidos en ese artículo la Administración "podrá repetir"; no dice deberá repetir. Por tal razón, en general se ha entendido que esta acción de repetición no obliga a la Administración sino que es facultativa. ${ }^{24}$

En el mismo sentido, con anterioridad, se había pronunciado Martins, quien recordó que el texto aprobado por la Cámara de Representantes establecía una fórmula imperativa, pero que fue modificada en la Cámara de Senadores en la que se adoptó el texto vigente. ${ }^{25}$

Entre los argumentos mencionados en la Cámara de Senadores para no adoptar la fórmula imperativa, Martins menciona los siguientes: "la inutilidad de seguir un juicio contra una persona notoriamente insolvente; la injusticia manifiesta de castigar tan duramente un funcionario con carrera irreprochable, que un día "por una desventura cualquiera, por una falla psicológica, por cualquiera de esos motivos, no siempre susceptibles de una mensura científica, pueda encontrarse con todas las apariencias de una conducta imprudente y grave, en un episodio cualquiera' (ECHEGOYEN); el daño que se le causa en su derecho a la carrera funcional al funcionario que se le sigue un juicio del que resulta definitivamente absuelto; el daño que se causa 'a la investidura de ese funcionario en su relación con los demás administrados, creándose un ambiente de suspicacia, de recelo, de desconfianza, planteándole una crisis de moralidad de ese agente del servicio público o titular de función pública determinada. En tercer término, por generalización de la situación, se causa daño a toda la administración en general, a todos los que actúan en cumplimiento de las funciones públicas, que se saben expuestas potencialmente a que cualquier error suyo en la conducta funcional, pueda dar mañana lugar a una acción

\footnotetext{
${ }^{24}$ SÁNCHEZ CARNELLI, L., "Responsabilidad de los funcionarios (artículo 25 de la Constitución)”, en Centro de Estudios de Derecho Público. Xo Coloquio de Derecho Público. F.C.U., Montevideo, 2006, p. 183.

25 MARTINS, D.H., "La responsabilidad...", loc. cit., p. 276.
} 
de repetición, sumándose el daño de orden moral, el indemnizatorio y los funcionales en cuanto al destino y carrera ulterior de ese funcionario.' (BAYLEY)." ${ }^{26}$

Sin perjuicio de reconocer la existencia de esos antecedentes señalados por Martins, estimo que el artículo 25 de la Constitución no otorga total libertad a la Administración para decidir si inicia o no una acción de repetición.

Una interpretación contextual de la Constitución teniendo en cuenta la noción de buena administración incluida en el artículo 311 de la Carta, ${ }^{27}$ nos hace pensar que el término "podrâ" del artículo 25 entraña un poderdeber. Si de las actuaciones administrativas seguidas como consecuencia del cumplimiento de una sentencia de condena por daños causados a terceros la Administración determina que el funcionario obró con dolo o culpa grave, no puede no iniciar una acción de repetición. No hacerlo constituye un acto de mala administración.

Esta interpretación contextual basta para rechazar la historia de la norma para la interpretación del artículo 25 en lo que refiere al significado del término "podrá". Y el concepto de buena administración lleva, además, al rechazo de todos los argumentos invocados en la Cámara de Senadores salvo el primero. En efecto, de los motivos dados en la Cámara de Senadores, solo en caso de insolvencia evidente del funcionario y en casos en que aparezca como evidente que el funcionario no va a devenir solvente se justifica no iniciar una acción de repetición en los casos en que el funcionario haya producido un daño actuando con dolo o culpa grave. También se podría admitir que no se inicie la acción de repetición si efectuada una evaluación de las probabilidades de éxito de acuerdo con el estado de la jurisprudencia, se estima que el resultado será adverso.

Fuera de esos casos excepcionales, la acción de repetición es un acto debido. No se puede olvidar nunca que la Administración no administra un patrimonio propio, sino ajeno.

\section{III}

1 Fuera de la hipótesis del artículo 25, que refiere a una responsabilidad hacia la Administración pero por daños causados a terceros, la

${ }^{26}$ MARTINS, D.H., "La responsabilidad...", loc. cit., p. 276 y ss.

27 DURÁN MARTínEZ, A., "Principio de eficacia y Estado subsidiario", en DURÁN MARTínEZ, A., Estudios de Derecho Público. Montevideo, 2008, v. 2, p. 9 y ss. 
Constitución no contiene expresamente normas que regulen la responsabilidad civil de los funcionarios públicos por daños directamente causados a la Administración. Como bien observó Martins, la Constitución solo alude al tema en forma indirecta. ${ }^{28}$

Las pocas normas constitucionales atinentes a la responsabilidad de los funcionarios hacia la Administración se encuentran en la Sección XIII destinada al Tribunal de Cuentas. De allí interesa el artículo 211 y el 213.

Del artículo 211, referido a la competencia del Tribunal de Cuentas, interesan para nuestro tema los literales C) y E).

Dichos literales dicen:

C) Dictaminar e informar respecto de la rendición de cuentas y gestiones de todos los órganos del Estado, inclusive Gobiernos Departamentales, Entes Autónomos y Servicios Descentralizados, cualquiera sea su naturaleza, así como también, en cuanto a las acciones correspondientes en caso de responsabilidad, exponiendo las consideraciones y observaciones pertinentes.

E) Intervenir en todo lo relativo a la gestión financiera de los órganos del Estado, Gobiernos Departamentales, Entes Autónomos y Servicios Descentralizados, y denunciar, ante quien corresponda, todas las irregularidades en el manejo de fondos públicos e infracciones a las leyes de presupuesto y contabilidad.

Por su parte, el artículo 213 - al referirse al proyecto de ley de Contabilidad y Administración Financiera que debe preparar el Tribunal de Cuentas - , al fijar su contenido refiere entre otras cosas a "las responsabilidades y garantías a que quedarán sujetos los funcionarios que intervienen en la gestión del patrimonio del Estado."

2 Como se percibe, la regulación de este tipo de responsabilidad queda remitida a la ley. Pero de esto no se debe seguir que la Constitución otorga un cheque en blanco al legislador. El precepto de interpretación conforme a la Constitución resaltado en tiempos de neoconstitucionalismo configura un importantísimo límite al legislador que impide que la ley regule la responsabilidad de modo que la neutralice. No se puede olvidar que la responsabilidad es inherente a la persona humana, tanto en lo que supone un derecho, derecho a obtener reparación por el daño sufrido, como en lo que supone deberes, deber de reparar el daño producido.

3 En este tema, además de las normas nacionales e internacionales destinadas al combate de la corrupción ${ }^{29}$ interesa especialmente lo dispuesto

\footnotetext{
${ }^{28}$ MARTINS, D.H., "La responsabilidad...", loc. cit., p. 335.

${ }^{29}$ DURÁN MARTÍNEZ, A., "Corrupción. Mecanismos sociales y jurídicos para su control", en DURÁN MARTíNEZ, A., Estudios de Derecho Público. Montevideo, 2008, v. 2, p. 89 y ss.
} 
en la ley de contabilidad y administración financiera en cuanto refiere a la responsabilidad de funcionarios públicos con tareas o funciones vinculadas a la gestión del patrimonio del Estado.

Este es precisamente el tema que a continuación trataré.

4 El Texto Ordenado de Contabilidad y Administración Financiera (TOCAF) destina el Título VI a las responsabilidades (arts. 119 a 130). Pero no son esa las únicas normas que regulan el punto; el propio TOCAF también alude a la responsabilidad en el artículo 62.

Analizaré en primer lugar el Título VI y luego el artículo 62 mencionados.

\section{IV}

1 El Título VI aludido refiere fundamentalmente a la responsabilidad administrativo y civil, pero también admite por esos mismos hechos que pueda comprometerse la responsabilidad penal o la política.

En efecto, el artículo 119, luego de establecer que "las transgresiones a las disposiciones a la presente ley constituyen faltas administrativas" y, por tanto, "en todos los casos los infractores estarán sujetos a las sanciones administrativas o disciplinarias aplicables", aclara que, cuando corresponda, también estarán sujetos "a las responsabilidades civiles, penales o políticas."

2 Siguiendo en líneas generales el esquema trazado en su momento por Martins, ${ }^{30}$ consideraré los siguientes puntos: a) a quienes alcanza la responsabilidad; b) cuándo surge la responsabilidad; c) cómo se comprueba la responsabilidad; d) cuándo prescribe la responsabilidad.

3 Conforme al artículo 119 del TOCAF, esta responsabilidad alcanza a todos los funcionarios públicos con tareas o funciones vinculadas a la gestión del patrimonio del Estado. También por disposición de esta ley alcanza a los jerarcas y empleados de las personas públicas no estatales, aunque no sean funcionarios estatales, que utilicen indebidamente fondos públicos o administren incorrectamente bienes del Estado.

Esta responsabilidad alcanza a todos los funcionarios que de alguna manera hayan intervenido en la acción comprometedora de la responsabilidad, ya sea jerarcas o subordinados, que ejerzan funciones de administración activa o pasiva, de asesoramiento o control, o que sin intervenir no se hayan opuesto debiendo hacerlo (art. 119).

30 MARTINS, D.H., "La responsabilidad ...", loc. cit., p. 337 y ss. 


\section{A título enunciativo, el artículo 120 del TOCAF incluye:}

1) A los obligados a rendir cuentas por las que hubieren dejado de rendir o por aquellas cuya documentación no fuere aprobada.

2) A los funcionarios de cualquier orden que dictaren resoluciones contrarias a las disposiciones de esta ley o su reglamentación.

3) A los funcionarios o agentes del Estado que por su culpa o negligencia, ocasionaron daños o perjuicios al Fisco, por entregas indebidas de bienes a su cargo o custodia, o por pérdida, sustracción o indebido uso, cuidado o mantenimiento de los mismos.

4) A los agentes recaudadores por las sumas que por su culpa o negligencia dejaren de percibir.

5) A los agentes recaudadores o pagadores que no depositen los fondos respectivos en la forma dispuesta en la presente ley o su reglamentación.

6) A los ordenadores de gastos y pagos por las obligaciones que asuman $u$ ordenen liquidar y pagar sin crédito previo suficiente, excepto en las circunstancias previstas en los artículos 15,17 y 19 de esta ley. ${ }^{31}$

7) Los funcionarios que tengan a su cargo la contabilidad en alguna o todas las etapas del gasto.

8) A los funcionarios de cualquier orden y a los jerarcas y empleados que incumplan con las obligaciones establecidas en la presente ley.

31 Esos artículos dicen:

"Art. 15. No podrán comprometerse gastos de funcionamiento o de inversiones sin que exista crédito disponible, salvo en los siguientes casos:

1) Cumplimiento de sentencias judiciales, laudos arbitrales o situaciones derivadas de lo establecido en los artículos 24 y 25 de la Constitución de la República.

2) Epidemias, inundaciones, incendios y todo tipo o forma de catástrofe cuya gravedad reclame la inmediata acción de los organismos públicos.

3) Cuando acontecimientos graves o imprevistos requieran la inmediata atención del Poder Ejecutivo o de las Intendencias Municipales en sus respectivas jurisdicciones. El monto de los créditos que, anualmente se podrá autorizar en uso de esta facultad, no podrá exceder al 1\% (uno por ciento) del Presupuesto Nacional o Departamental (artículos 214 y 222 de la Constitución de la República), respectivamente.

En estos casos se dará cuenta inmediata a la Asamblea General, Comisión Permanente o Junta Departamental que corresponda, lo que se ordenará en el mismo acto administrativo. En los casos previstos en los numerales 2) y 3) las resoluciones deberán dictarse privativamente por el Poder Ejecutivo o Intendencia Municipal según su jurisdicción."

"Art. 17. No podrán comprometerse gastos de funcionamiento o de inversiones, cuyo monto exceda el límite de la asignación anual, salvo los siguientes casos:

1) Para el cumplimiento de leyes cuya vigencia exceda de un ejercicio financiero.

2) Para la locación de inmuebles, obras o servicios sobre cuya base sea la única forma de asegurar la regularidad y continuidad de los servicios públicos o la irremplazable colaboración técnica o científica especial. 3) Para las operaciones de crédito, por el monto de los correspondientes servicios financieros, amortizaciones, intereses, comisiones y otros gastos vinculados.

No obstante lo dispuesto precedentemente, el monto de la afectación anual no podrá exceder el límite del crédito anual respectivo."

"Art. 19. No podrán comprometerse gastos cuya realización se haya condicionado a la existencia previa de recursos especiales, si no se hubiera realizado la recaudación de los mismos.

No obstante, el ordenador del gasto podrá disponerlo si por las características del recurso puede tenerse la certeza de su efectiva financiación dentro del ejercicio. Las resoluciones que autoricen créditos para gastar con cargo a dichos recursos establecerán expresamente el régimen de financiación aplicable." 
El artículo 121 establece la responsabilidad mancomunada y solidaria de todos los funcionarios que resuelvan, dispongan, ejecuten o intervengan en la formación de actos u ocurrencia de hechos generadores de la responsabilidad a que refiere el artículo 119.

Aunque no lo dice expresamente, esto refiere a la responsabilidad civil, puesto que no es concebible la solidaridad en el ámbito de la responsabilidad administrativa.

También este artículo exceptúa de la responsabilidad a los integrantes de órganos colegiados que se hubieren opuesto al acto y dejado constancia escrita de su oposición, así como a los funcionarios sometidos a jerarquía que también hubiesen asentado por escrito su oposición al acto o hecho generador de la responsabilidad. Aunque nada se especifica al respecto, es obvio que esta eximente de responsabilidad obra en todos los tipos de responsabilidad.

4 La responsabilidad administrativa en los casos en estudio se compromete aun cuando no se ocasionen perjuicios económicos al Estado (art. 119, inciso cuarto).

La responsabilidad civil requiere, para ser comprometida, la existencia de un daño. Ese daño puede ser de tipo patrimonial pero también moral.

En estos casos, tanto en lo que refiere a la responsabilidad administrativa como a la civil, estamos ante supuestos de responsabilidad que obedecen a criterios subjetivos de imputación. Es decir, es preciso que haya existido algún tipo de culpabilidad, en cualquiera de sus grados, incluida cualquier hipótesis de ilegitimidad, aunque esa ilegalidad no se haya cometido con conciencia y voluntad. Entre esas hipótesis de ilegitimidad comprendemos no solamente la violación a cualquier regla de derecho sino también a los criterios de buena administración. ${ }^{32}$ Menciono expresamente la noción de buena administración porque aunque a mi juicio ella queda subsumida en la de regla de derecho, otros piensan distinto.

Sobre el punto, el inciso tercero del artículo 119 es muy claro:

La responsabilidad administrativa se genera por el apartamiento de las normas aplicables, de los objetivos y metas previstos, y el apartamiento inexcusable de los principios y procedimientos de buena administración, en todos los casos en lo relativo al manejo de dineros o valores públicos y a la custodia o administración de bienes estatales.

32 DURÁN MARTíneZ, A., "Principio de eficacia...", loc. cit., p. 9 y ss.; DURÁN MARTíneZ, A., Contencioso Administrativo. F.C.U., Montevideo, 2007, p. 295 y ss. 
No estamos pues ante supuestos de responsabilidad objetiva.

De más está decir que tanto en la responsabilidad administrativa como en la civil se puede responder por la llamada culpa in vigilando. Claro está que esto debe ponderarse con criterios de razonabilidad. La razonabilidad está presente en todo el Derecho, pero en estos casos cobra especial importancia.

5 La responsabilidad administrativa se determina mediante un procedimiento administrativo en el que puede intervenir el Tribunal de Cuentas de la República, y que por cierto deberá respetar todas las normas relacionadas con el debido procedimiento (arts. 122 y ss).

Como ese procedimiento concluye con un acto administrativo y este es susceptible de los recursos administrativos correspondientes y de la acción de nulidad, en definitiva la última palabra en materia de responsabilidad administrativa la tiene el Tribunal de lo Contencioso Administrativo. Dicho de otro modo, esta responsabilidad se determina en vía administrativa pero eventualmente queda supeditada a lo que en definitiva se resuelva en vía jurisdiccional.

También la determinación de la responsabilidad civil comienza, o puede comenzar, en sede administrativa. Es que en el aludido sumario o investigación administrativa se puede determinar la responsabilidad del funcionario, el daño producido y su monto. Y en función de ello, la Administración podrá iniciar la acción judicial correspondiente para hacer efectiva la responsabilidad civil.

En estos casos de la actuación administrativa podrá surgir una presunción de la responsabilidad civil del infractor (art. 124). En tal hipótesis, "a los efectos de la acción civil, el testimonio de la resolución administrativa y en coincidencia con el dictamen del Tribunal de Cuentas, constituirá presunción simple de la entidad del perjuicio a reclamar" (art. 129, numeral $4^{\circ}$ ).

Como se ha dicho, estamos en presencia de una presunción simple, o sea, esta admite prueba en su contra. De manera que también esta responsabilidad en última instancia se determina en vía jurisdiccional.

Ambas responsabilidades son independientes, pueden acumularse, puede existir la administrativa sin la civil, pero no la civil sin la administrativa.

El Juez de la responsabilidad civil queda atado por la cosa juzgada de la sentencia pronunciada por el Tribunal de lo Contencioso Administrativo en cuanto acoge la acción de nulidad, pero si la rechaza no 
necesariamente debe condenar porque para ello corresponde la acreditación del daño. Por otro lado, si no existe acción de nulidad o si esta se desestima por falta de algún requisito de admisibilidad, el Juez del Poder Judicial puede analizar la legitimidad de los actos administrativos pertinentes y sin anularlos fallar en consecuencia.

6 Conforme al artículo 127 del TOCAF estas responsabilidades, la administrativa y la civil, prescriben a los diez años a partir de la fecha del acto o hecho que diera origen a las mismas. En caso de funcionarios que deban ser sometidos al previo juicio político, el término de prescripción comenzará a contarse a partir del cese en el cargo.

El cese del funcionario impide la responsabilidad administrativa pero no la civil, la que puede hacerse efectiva mientras no esté prescripta.

El artículo 126 establece expresamente que el cese de funciones no exime de responsabilidad civil al ex funcionario. Y, a mayor abundamiento, aclara que la renuncia o separación del cargo del funcionario responsable no impide ni paraliza el examen de sus cuentas y gestión en el manejo de bienes y fondos públicos, ni las acciones civiles de resarcimiento que pudiera corresponder. ${ }^{33}$

$1 \mathrm{El}$ artículo 62 del TOCAF contiene normas especiales en materia de recursos administrativos interpuestos contra actos dictados en el ámbito de procedimientos de contratación. ${ }^{34}$

$2 \mathrm{Su}$ inciso final refiere a aspectos de responsabilidad en que pueden incurrir las personas que de alguna manera intervienen en estos procedimientos.

Ese inciso final dice:

Resuelto el recurso, se apreciarán las responsabilidades de los órganos o funcionarios responsables y del propio recurrente. Si éste hubiere actuado con mala fe o con manifiesta falta de fundamento, se le aplicarán sanciones de suspensión o eliminación del Registro de Proveedores y Contratistas del Estado; ello sin perjuicio de las acciones judiciales que pudieran corresponder por reparación del daño causado a la Administración.

\footnotetext{
${ }^{33}$ No obstante lo expresado, el mismo artículo 126 exime de responsabilidad civil al ex funcionario: 1) Por su gestión financiero-patrimonial incluida en rendiciones de cuentas aprobadas por los órganos de control. 2) Por los bienes a su cargo o custodia descargados en la forma dispuesta por los artículos 115 y 116 . 3) Por los descargos de inventarios que hubieren sido aprobados por los órganos de control."

34 DURÁN MARTíNEZ, A., "Particularidades del régimen recursivo en los procedimientos de contratación administrativa", en DURÁN MARTínEZ, A., Estudios de Derecho Público..., v. 2, p. 157 y ss.
} 
3 Como se percibe, esta norma refiere a la apreciación de las responsabilidades de todos los que han intervenido en el procedimiento de contratación. Impone pues, expresamente, que la Administración evalúe las responsabilidades del caso.

4 Esa evaluación de responsabilidad se efectúa tanto respecto de los que actúan por el sector público como respecto de los que actúan por el sector privado. En efecto, alude por un lado a órganos o funcionarios y por otro lado al recurrente.

En todos estos casos estamos ante una responsabilidad hacia la Administración. Me referiré únicamente a la responsabilidad de los funcionarios.

$5 \mathrm{El}$ giro empleado por la ley al referirse a la apreciación de las responsabilidades de los órganos y de los funcionarios es poco técnico pero ilustra acerca de la amplitud del alcance del control. La Administración debe evaluar la responsabilidad de todos los funcionarios intervinientes, incluso la de los titulares de los órganos.

6 La causa generadora de la responsabilidad a los efectos de este artículo es distinta según se trate de los funcionarios, incluidos los titulares de los órganos, o según se trate del recurrente.

En el primer caso ella es de máxima amplitud: comprende cualquier conducta que haya provocado una irregularidad y cualquiera sea el grado de culpabilidad. En el caso del recurrente, la responsabilidad se compromete únicamente en caso de haber actuado con mala fe o con manifiesta falta de fundamentos.

$7 \mathrm{El}$ control respecto de los funcionarios lo efectúa la Administración. Lo puede hacer al resolver el respectivo recurso, pero siempre en el ámbito de la competencia del órgano actuante.

En el caso de los recursos de revocación y jerárquico, la Administración aplicará los poderes inherentes a la jerarquía si los tiene, y en el grado en que los tenga. En el caso del recurso de anulación, el Poder Ejecutivo podrá poner en marcha los mecanismos de los artículos 197 y 198 de la Constitución.

En este último caso, este control versará sobre los titulares del órgano jerarca del Servicio Descentralizado correspondiente puesto que la responsabilidad administrativa de los funcionarios del ente se debe hacer efectiva por medio de su jerarca.

8 La sanción que debe recaer en caso de los funcionarios dependerá de la gravedad de la falta y se hará efectiva previo cumplimiento de las reglas del debido procedimiento. 
De esas actuaciones administrativas podrá surgir, además, si se ha comprometido o no la responsabilidad civil del funcionario o la penal o incluso la política. Y en caso afirmativo, para hacer efectivas esas responsabilidades se deberá proceder por la vía que corresponda.

9 Lamentablemente, las responsabilidades previstas en este artículo 62 rara vez se han hecho valer.

\section{VI}

1 Las tesis tradicionales que ahora hemos combatido llevaron, naturalmente que sin proponérselo, a la existencia de lo que Delpiazzo llamó y se propuso erradicar, en un reciente trabajo de certero enfoque, sujetos irresponsables y reductos de irresponsabilidad. ${ }^{35}$

A menudo, así, los funcionarios han adquirido una sensación de invulnerabilidad y gracias a esa impunidad han ocasionado daños a terceros y a la Administración que pudieron haberse evitado.

2 Precisamente, nuestra interpretación dey desde la Constitución, como decía Bidart Campos ${ }^{36}$ o, mejor aun, desde la dignidad de la persona humana, ${ }^{37}$ más acorde a las tendencias actuales del Derecho Constitucional, evita esas islas de irresponsabilidad y permite la realización integral del Derecho. Se logra así una mayor trasparencia y una adecuada comunión entre la ética y el Derecho.

3 No se me oculta que una incorrecta aplicación del Derecho en nuestra interpretación puede provocar situaciones no deseables. En efecto, puede alentar a reclamaciones temerarias contra los funcionarios, tanto por parte de terceros como por parte de la Administración que puede hacer que solo estén dispuestos a asumir la función pública los insolventes; o puede provocar una actitud de excesiva cautela del funcionario que, para evitar incurrir en riesgos, opta más por no hacer que hacer, ya que es más probable que se le responsabilice por acción que por omisión, lo que redunda en definitiva en la ineficacia de la Administración.

35 DELPIAZZO, C.E., "La responsabilidad en el derecho público uruguayo", en Revista de Derecho. Publicación arbitrada de la Universidad Católica del Uruguay. Universidad Católica del Uruguay/ Konrad Adenauer. Stiftung. Montevideo, 2008, n. 3, p. 62.

36 BIDART CAMPOS, G.J., Teoría general de los derechos humanos, Astrea, Buenos Aires, 1991, p. 376 y ss.

37 DURÁN MARTÍNEZ, A., "Los principios generales del derecho en el derecho administrativo uruguayo. Aplicación por el legislador, el administrador y el juez", en Los principios en el derecho administrativo iberoamericano. Junta de Castilla y León/ Escuela de Administración Pública de Castilla y León/ Foro Iberoamericano de Derecho Administrativo. La Coruña, 2008, p. 606. 
Ese riesgo - cierto, desde luego - se diluye con razonabilidad. El Estado debe así ser exigente y ponderado a la vez, teniendo en cuenta las circunstancias de cada caso, y adoptar una actitud eficazmente protectora del buen funcionario ante las demandas infundadas que pueda recibir.

Solo así se puede realizar propiamente el derecho, porque si la eficacia se ve afectada - el principio de eficacia es de la esencia del Estado de Derecho $-{ }^{38}$ no se realiza el derecho. La ética y la eficacia no son incompatibles; antes bien, logran su perfecta armonía en el plano jurídico.

\title{
The Responsibility Before the Administration in the Uruguayan Administrative Law
}

\begin{abstract}
The present article is about the responsibility before the Administration in the Uruguayan Administrative law. First general aspects of the responsibility are demonstrated. It is approached the civil responsibility of the public officers, ahead of the Constitution of 1934, the Amendment of 1942 and the Constitution of 1952. Interpretations of doctrines are cited on the constitutional ruleses that conduct the subject of the responsibility of the public officers. After that, the foreseen hypotheses of to hold responsibility for in article 25 of the Constitution of 1952 are analyzed. Some articles of the TOCAF - Commanded Text of Accounting and Financial Administration - with the administrative and civil responsibility become related. One mentions that for the existence of the civil liability the existence of a damage is necessary, that can be patrimonial and moral. Finally, it is supported that the Constitution must be interpreted in accordance with the principle of dignity of the human person and with the current trends of the Constitucional law, to prevent irresponsabilidades and to allow the integral realization of law.
\end{abstract}

Keywords: Uruguayan administrative law. Civil responsability of the public officers. Constitution. Commanded Text of Accounting and Financial Administration. Damage.

Informação bibliográfica deste texto, conforme a NBR 6023:2002 da Associação Brasileira de Normas Técnicas (ABNT):

DURÁN MARTíNEZ, Augusto. La responsabilidad hacia la Administración en el Derecho Administrativo uruguayo. A\&C - Revista de Direito Administrativo e Constitucional, Belo Horizonte, ano 9, n. 35, p. 195-213, jan./mar. 2009.

Recebido em: 20.1.09

Aprovado em: 27.2.09

38 DURÁN MARTínEZ, A., "Principio de eficacia...", loc. cit., p. 19. 